\title{
Dioscorea alata as Alternative Culture Media for Fungal Cultivation and Biomass Production
}

\author{
Suwapha Sawiphak ${ }^{1 *}$, Aroon Wongjiratthiti ${ }^{1}$ and Chanankarn Saengprasan ${ }^{2}$ \\ ${ }^{1}$ Program of Biology, Faculty of Science and Technology, Sakon Nakhon Rajabhat University, \\ Sakon Nakhon, Thailand \\ ${ }^{2}$ Program of Mathematics and Statistics, Faculty of Science and Technology, Sakon Nakhon Rajabhat University, \\ Sakon Nakhon, Thailand
}

\begin{abstract}
Dioscorea alata (purple yam) is a tuber crop that contains plenty of nutrients. It is widely cultivated in Thailand, but it is underutilized. In this study, the suitability of purple yam to replace potato dextrose media for fungal growth was investigated. Mushrooms and molds were grown on purple yam dextrose agar (PYDA), whereas yeasts were cultured in purple yam dextrose broth (PYDB). Response surface methodology (RSM) with Box-Behnken design (BBD) was used to optimize the culture conditions for Saccharomyces cerevisiae biomass production. The growth profile of $S$. cerevisiae in PYDB under optimized culture conditions was also studied. All test mushrooms and molds recorded the highest colony diameter and mycelial dry weight on PYDA containing $40 \%$ purple yam. Similar to mushrooms and molds, yeasts in PYDB with 40\% purple yam showed the highest number of cells. The growth of fungi on purple yam dextrose media was significantly higher than those on potato dextrose media under standard conditions. The optimal conditions from the RSM results for the biomass production of $S$. cerevisiae in PYDB were purple yam concentration of $49.61 \%$, dextrose concentration of $4.87 \%$, $\mathrm{pH}$ value of 5.74 , and inoculum size of $7.00 \%$. The biomass of S. cerevisiae in PYDB under the optimal conditions obtained from the results of the optimization by RSM was thirty times higher than $S$. cerevisiae biomass in potato dextrose broth under

ARTICLE INFO

Article history:

Received: 09 January 2021

Accepted: 11 March 2021

Published: 28 May 2021

DOI: https://doi.org/10.47836/pjtas.44.2.05

E-mail addresses:

ssuvapa@hotmail.com (Suwapha Sawiphak)

mic_610@hotmail.com (Aroon Wongjiratthiti)

chanankarn@snru.ac.th (Chanankarn Saengprasan) standard conditions. Our results suggest that purple yam could be an alternative to potato dextrose media for fungal cultivation.

Keywords: Biomass production, Box-Behnken design, Dioscorea alata, fungal growth, purple yam, response surface methodology, statistical optimization
\end{abstract}

* Corresponding author 


\section{INTRODUCTION}

Fungi are eukaryotic organisms comprising multicellular (molds and mushrooms) and unicellular (yeasts) fungi, and are chemoheterotrophs which assimilate the organic compounds as energy and nutritional sources for their growth (Singh \& Kapoor, 2010). Macro and micronutrients are essential for fungal growth and reproduction (Wongjiratthiti \& Yottakot, 2017).

Potato dextrose media are major media for the isolation and cultivation of fungi under laboratory conditions (Laurie et al., 2015). In Thailand, potato is rarely cultivated and only grown in three provinces (Tak, Chiang Mai, and Chiang Rai provinces) (Kittipadakul et al., 2016), and is so much expensive than the other local crops (https://www.simummuangmarket.com/ en). The fungal cultivation using powdered potato dextrose media (commercial) is expensive. The utilization of agricultural crops as alternative culture media in the cultivation of fungi was studied (Adesemoye \& Adedire, 2005; Amadi \& Moneke, 2012; Nguyen \& Ranamukhaarachchi, 2020; Wongjiratthiti \& Yottakot, 2017). There are underutilized agricultural crops in Thailand. Dioscorea alata (purple yam) is one of the underutilized local crops, although it contains many essential nutrients such as carbohydrate, protein, potassium, sodium, phosphorus, calcium, and magnesium (Chandrasekara \& Kumar, 2016; Wanasundera \& Ravindran, 1994), and is widely cultivated in the north-eastern region of Thailand especially Sakon Nakhon and Kalasin provinces. The utilization of purple yam tuber as alternative culture media for fungal cultivation is seldom reported. Moddaeng and Khompun (2019) showed that purple yam was a suitable alternative tuber to media preparation for the cultivation of Curvularia lunata and Fusarium solani.

Saccharomyces cerevisiae is useful yeast involved in many industrial processes such as starter cultures, enzyme production (Arevalo-Villena et al., 2017), and alcoholic fermentation (Shiroma et al., 2013). The growth of yeast depends on different culture conditions, such as culture medium components and their concentrations, $\mathrm{pH}$ of culture medium, inoculum size, and others (Jiru et al., 2017; Mad Saad et al., 2016; Shu et al., 2020). The high biomass yield can be beneficial for industries related to $S$. cerevisiae. The optimization of cultivation conditions using single factor experiment in a step-by-step fashion cannot understand an interaction between the factors. Response surface methodology (RSM) is successfully operated to optimize the process factors and it can give data about the interaction between factors (Dinarvand et al., 2017; Sharmila et al., 2013). Box-Behnken design (BBD) is an experimental design for RSM, and it can help to reduce the number of experimental trials (Tayeb et al., 2018).

The possibility of purple yam utilization as alternative culture media for fungal cultivation was studied by assessing the effect of purple yam at various concentrations on the mycelial growth of test mushrooms 
and molds on purple yam agar media and the growth of test yeasts in purple yam broth media. The culture conditions for $S$. cerevisiae biomass production in purple yam broth medium such as medium (purple yam and dextrose concentration), $\mathrm{pH}$ of the culture medium, and inoculum size were optimized through RSM based on BBD. The growth profile of $S$. cerevisiae in purple yam broth medium under the optimized culture conditions was also investigated. The biomass production of $S$. cerevisiae in purple yam broth medium was studied as an example of the utilization of purple yam in further fungal cultivation and biomass production.

\section{MATERIALS AND METHODS}

\section{Test Fungi and Crop Materials}

Three species of each mushroom, mold, and yeast were used as representatives of fungi in the study of purple yam utilization for fungal cultivation. The test mushrooms were Pleurotus eryngii (PE), Pleurotus sajor-caju (Fr.) Singer (PS), and Pleurotus ostreatus (Fr.) Kummer (PO). The test molds were Bipolaris oryzae DOAC 1760, Fusarium oxysporum, and Penicillium $\mathrm{sp}$. The test yeasts were Saccharomyces cerevisiae, Saccharomyces boulardii, and Rhodotorula sp. All test organisms were collected in the Program of Biology, Faculty of Science and Technology, Sakon Nakhon Rajabhat University, Thailand. Purple yam (Dioscorea alata) was obtained from the local farmers in Sakon Nakhon province, Thailand.

\section{Media Preparation}

The growth of test fungi was carried out in potato dextrose media as control media and purple yam dextrose media as test media. Different media were formulated, namely purple yam dextrose media [purple yam dextrose agar (PYDA), purple yam dextrose broth (PYDB)], potato dextrose media [potato dextrose agar (PDA), potato dextrose broth (PDB)] (Difco ${ }^{\mathrm{TM}}$, France) and dextrose media [dextrose agar (DA), dextrose broth (DB)]. The purple yam infusion was prepared according to the method of Wongjiratthiti and Yottakot (2017). The purple yam was washed with water, peeled, and diced. The diced purple yam at various concentrations was boiled in distilled water at $100^{\circ} \mathrm{C}$ for $15 \mathrm{~min}$ and then filtered through cheesecloth. The filtrates were added with different dextrose concentrations (HiMedia Laboratories, India). The DB contains only $2.0 \%(\mathrm{w} / \mathrm{v})$ of dextrose. The agar media (PYDA and DA) were prepared by adding $2.0 \%(\mathrm{w} / \mathrm{v})$ of agar (Biomark Laboratories, India) to broth media. The $\mathrm{pH}$ of all media was adjusted with $\mathrm{HCl}$ or $\mathrm{NaOH}$ before sterilization in an autoclave at $121^{\circ} \mathrm{C}$ for $15 \mathrm{~min}$. After sterilization, PDA, PYDA, and DA were allowed to cool down to around $60^{\circ} \mathrm{C}$ and poured into petri dishes ( $9 \mathrm{~cm}$ diameter). The PDB, PDA, DA, and DB were used as control media. The $\mathrm{pH}$ of all media was adjusted to $\mathrm{pH} 5.1 \pm 0.2$. 


\section{Effect of Purple Yam at Different Concentrations on the Mycelial Growth of Mushrooms and Molds}

Pure cultures of the test mushrooms and molds from PDA slants at $4^{\circ} \mathrm{C}$ were transferred on PDA plates. All plates were incubated at $25^{\circ} \mathrm{C}$ for $168 \mathrm{~h}$. An agar plug (6 mm diameter) of each mushroom and mold mycelium was placed onto the center of the test agar media under aseptic condition and incubated at $25^{\circ} \mathrm{C}$ for $168 \mathrm{~h}$. The mycelial growth of test filamentous fungi was evaluated on six different agar media including PYDA at four concentrations of purple yam [10, 20, 30, and 40\% (w/v)], DA, and PDA. After incubation, the colony diameter was measured using a vernier caliper, and mycelial dry weight was determined. To determine the mycelial dry weight, the mycelium with agar media was melted in a microwave oven for 20 $\mathrm{s}$ at $800 \mathrm{~W}$. After that, the mycelium was filtered from the medium, rinsed with hot distilled water (about $60^{\circ} \mathrm{C}$ ), and dried in a hot air oven at $105^{\circ} \mathrm{C}$ until constant in weight (Vargas-Isla \& Ishikawa, 2008). The experiment was performed in triplicates. The results were analyzed by one-way analysis of variance (ANOVA) and mean differences were considered significant at $p$ $<0.05$ by Tukey's HSD post hoc multiple comparison test.

\section{Effect of Purple Yam at Different Concentrations on the Growth of Yeasts}

Pure cultures of the test yeasts from PDA slants at $4^{\circ} \mathrm{C}$ were transferred into flasks containing PDB. Flasks were incubated at $30^{\circ} \mathrm{C}$ under shaking at $180 \mathrm{rpm}$ for 24 h. After $24 \mathrm{~h}$, the cells were harvested by centrifugation at 5,635 $\mathrm{x}$ g for $10 \mathrm{~min}$ and were washed twice with sterile $0.85 \%$ (w/v) $\mathrm{NaCl}$. The yeast precipitates were resuspended in sterile distilled water. The inoculum density of the yeast suspensions was adjusted to an optical density at 600 nm (OD600) of 0.34 (McFarland standard No. 1, India). Each flask of the broth media was inoculated with $3 \%(\mathrm{w} / \mathrm{v})$ of inoculum and incubated in a shaker at $30^{\circ} \mathrm{C}$ and 180 rpm for $24 \mathrm{~h}$. The growth of test yeasts in six broth media including PYDB at four concentrations of purple yam [10, 20, 30, and $40 \%(\mathrm{w} / \mathrm{v})]$, DB, and PDB was enumerated using a hemocytometer (Wongjiratthiti \& Yottakot, 2017). The experiment was done in triplicates. The results were analyzed by one-way ANOVA and mean differences were considered significant at $p<0.05$ by the Tukey method.

\section{Optimization of Culture Conditions for Saccharomyces cerevisiae Biomass Production in PYDB}

Purple yam concentration, dextrose concentration, $\mathrm{pH}$, and inoculum size were optimized by response surface methodology (RSM) using Box-Behnken design for the biomass production of Saccharomyces cerevisiae in PYDB. The conditions for the biomass production in $S$. cerevisiae were optimized as described in Table 1. The number of $S$. cerevisiae was counted with a hemocytometer under a microscope after $24 \mathrm{~h}$ of incubation. 
Table 1

Experimental code and levels of the factors in $B B D$

\begin{tabular}{lcccc}
\hline \multicolumn{1}{c}{ Factors } & Code & \multicolumn{3}{c}{ Levels } \\
\cline { 3 - 5 } & & -1 & 0 & 1 \\
\hline Purple yam concentration (\% w/v) & $A$ & 10 & 30 & 50 \\
Dextrose concentration (\% w/v) & $B$ & 1 & 3 & 5 \\
$\mathrm{pH}$ & $C$ & 3 & 5 & 7 \\
Inoculum size (\% w/v) & $D$ & 3 & 5 & 7 \\
\hline
\end{tabular}

\section{Determination of Growth Profile of Saccharomyces cerevisiae in PYDB}

Saccharomyces cerevisiae cultured in 100 mL PYDB medium with optimal conditions from RSM was incubated at $30^{\circ} \mathrm{C}$ under shaking condition of $180 \mathrm{rpm}$. The growth of $S$. cerevisiae was taken every $6 \mathrm{~h}$ during an incubation period of $48 \mathrm{~h}$.

\section{RESULTS AND DISCUSSION}

\section{Effect of Purple Yam at Different} Concentrations on the Mycelial Growth of Mushrooms and Molds

Results of the experiment clearly indicated that significantly highest colony diameter and mycelial dry weight of all test mushrooms and molds were found on PYDA media at $40 \%(\mathrm{w} / \mathrm{v})$ purple yam (Figures $1 \mathrm{~A}-\mathrm{C}$ and 2A-C). The colony diameter and mycelial dry weight of all mushrooms and molds on PYDA at $40 \%(\mathrm{w} / \mathrm{v})$ purple yam were significantly higher than PDA and DA (control media) suggesting that purple yam is rich in essential nutrients for fungal mycelial growth. DA cannot promote the growth of all mushrooms and molds mycelium. Earlier findings by Moddaeng and Khompun (2019) also found that purple yam dextrose agar was a suitable medium for the cultivation of Curvularia lunata and Fusarium solani. Fungal growth under laboratory conditions is dependent on the nutrients in media, which are important for growth, survival, and reproduction (Hoa \& Wang, 2015; Wongjiratthiti \& Yottakot, 2017). Chandrasekara and Kumar (2016) reported that purple yam has a higher carbohydrate, energy, vitamins (thiamine, riboflavin, and vitamin B6), and minerals (calcium, magnesium, and potassium) than potato. These nutrients are important factors for the growth of molds (Uraz \& Özer, 2014) and mushrooms (Bellettini et al., 2019).

Although, the mycelial growth of PE and PS at 20\% (w/v) purple yam concentration was less than PDA, the increase of the purple yam concentration up to $40 \%(\mathrm{w} / \mathrm{v})$ led to the mycelial growth of PE and PS was higher than PDA. The concentration of culture media components had an effect on mycelial growth (Xiao et al., 2004). The result indicated that PYDA media at $40 \%$ $(\mathrm{w} / \mathrm{v})$ purple yam had the possibility to use as substitutes for PDA in the cultivation of mushrooms and molds mycelium.

\section{Effect of Purple Yam at Different Concentrations on the Growth of Yeasts}

The effect of purple yam at different concentrations of growth media on $S$. 


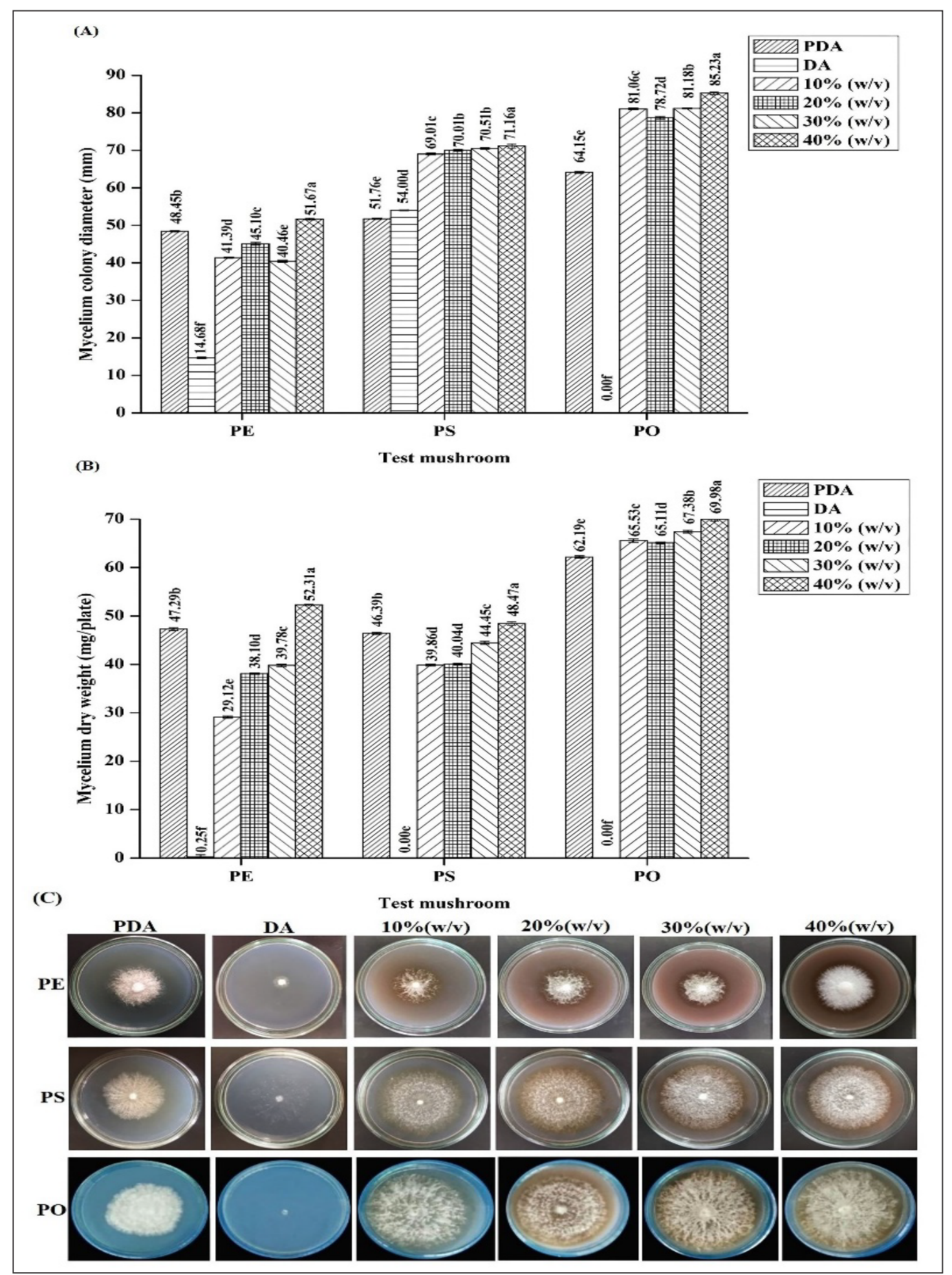

Figure 1. (A) Colony diameter, (B) dry weight, and (C) mycelium growth of Pleurotus eryngii (PE), Pleurotus sajor-caju (Fr.) Singer (PS), and Pleurotus ostreatus (Fr.) Kummer (PO) on different agar media after $168 \mathrm{~h}$ of incubation at $25^{\circ} \mathrm{C}$

Note. A pair of averages with different letters is considered significantly different at $p<0.05$ 


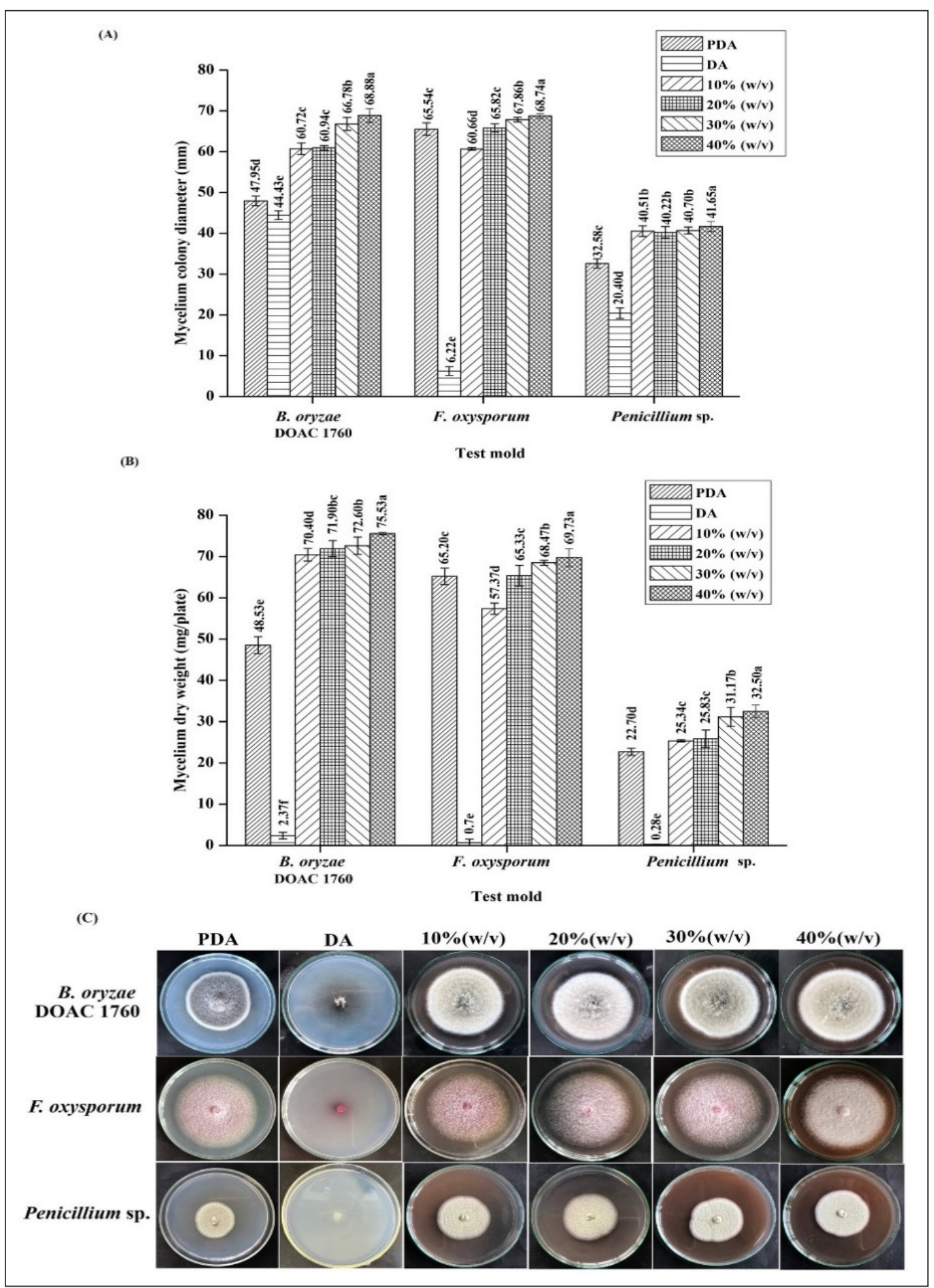

Figure 2. (A) Colony diameter, (B) dry weight, and (C) mycelium growth of Bipolaris oryzae DOAC 1760, Fusarium oxysporum, and Penicillium sp. on different agar media after $168 \mathrm{~h}$ of incubation at $25^{\circ} \mathrm{C}$ Note. A pair of averages with different letters is considered significantly different at $p<0.05$ 
cerevisiae, S. boulardii, and Rhodotorula sp. was tested (Figure 3). The highest number of $S$. cerevisiae, $S$. boulardii, and Rhodotorula sp. were obtained in PYDB media at $40 \%(\mathrm{w} / \mathrm{v})$ purple yam with the cell number of $7.69 \times 10^{6} \pm 0.40,3.09 \times$ $10^{7} \pm 0.20$, and $3.45 \times 10^{7} \pm 0.25$ cells $/ \mathrm{mL}$, respectively. The growth of all test yeasts in $40 \%(\mathrm{w} / \mathrm{v})$ PYDB was significantly higher than in the standard culture medium (PDB), DB, and the other purple yam concentrations, because purple yam is rich in sugars, carbohydrates, proteins, vitamins (riboflavin, vitamin B6, and thiamine), and minerals (calcium, magnesium, phosphorus, sodium, and potassium) (Chandrasekara \& Kumar, 2016; Wanasundera \& Ravindran, 1994). These nutrients play an important role for cellular metabolism (such as the biosynthesis of nucleic acids, phospholipids, and ATP), growth and multiplication of two test Saccharomyces species (Farinazzo et al., 2017; Walker \& Stewart, 2016) and Rhodotorula sp. (especially phosphorus) (Kot et al., 2019). Thiamine, which is high in purple yam (Chandrasekara \& Kumar, 2016), is an essential coenzyme in carbohydrate and amino acid metabolism, and could promote the growth of yeasts (Hucker et al., 2016; Li et al., 2010).

\section{Optimization of Culture Conditions for Saccharomyces cerevisiae Biomass Production in PYDB}

Saccharomyces cerevisiae is recognized as a model organism (Karathia et al., 2011; Parapouli et al., 2020) and a most valuable species in various industrial applications (Arevalo-Villena et al., 2017; Shiroma et al., 2013; Parapouli et al., 2020). The optimization of culture conditions for $S$. cerevisiae biomass production in PYDB

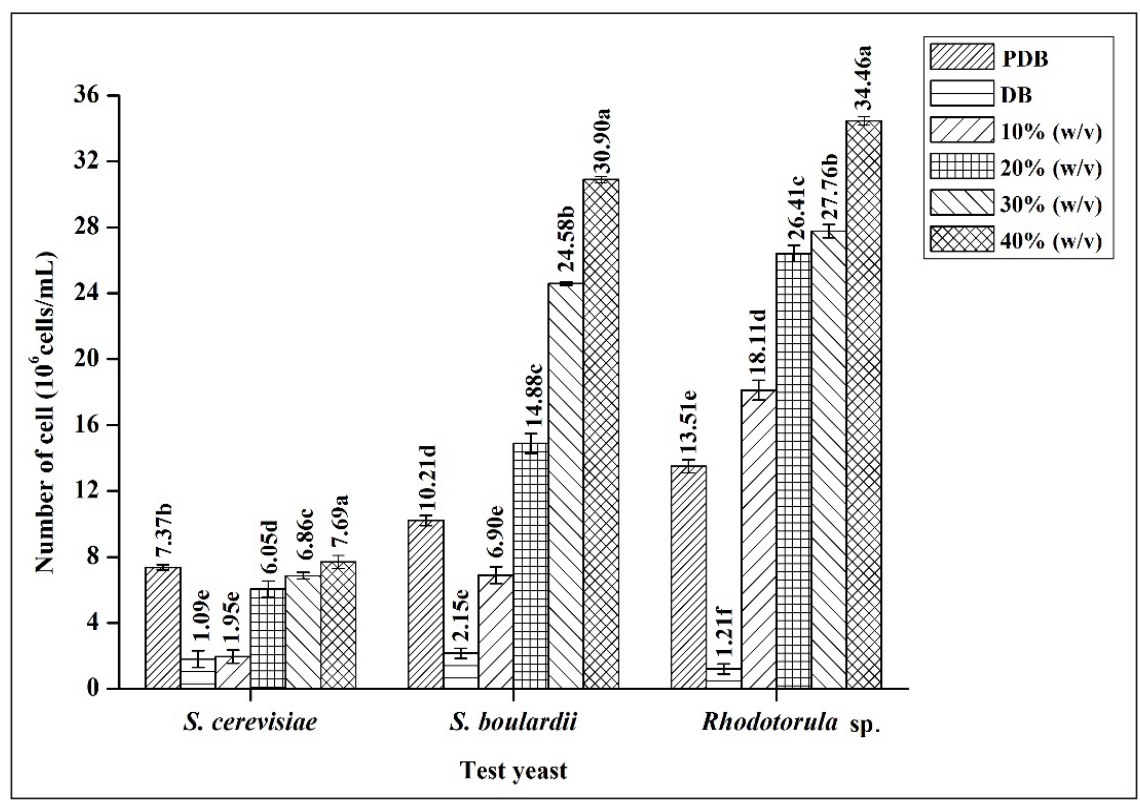

Figure 3. The growth of the test yeasts in different broth media for $24 \mathrm{~h}$

Note. A pair of averages with different letters is considered significantly different at $p<0.05$ 
was examined through RSM with BBD. a second-order polynomial equation to Twenty-nine experiments based on BBD predict the optimal culture conditions of with three levels of each factor and their $S$. cerevisiae in PYDB. The number of $S$. actual and predicted responses are shown in cerevisiae in PYDB follows the response Table 2. The experimental results received surface regression model [1]. from BBD (actual values) were fitted to

\section{Table 2}

The Box-Behnken experimental design for Saccharomyces cerevisiae biomass production and their actual and predicted responses

\begin{tabular}{|c|c|c|c|c|c|c|}
\hline \multirow{2}{*}{ STD } & \multirow{2}{*}{ Factor $A$} & \multirow{2}{*}{ Factor $B$} & \multirow{2}{*}{ Factor $C$} & \multirow{2}{*}{ Factor $D$} & \multicolumn{2}{|c|}{ Biomass (cells $/ \mathrm{mL}$ ) } \\
\hline & & & & & Actual value & Predicted value \\
\hline 1 & 10 & 1 & 5 & 5 & $5.60 \times 10^{7}$ & $5.94 \times 10^{7}$ \\
\hline 2 & 50 & 1 & 5 & 5 & $1.42 \times 10^{8}$ & $1.49 \times 10^{8}$ \\
\hline 3 & 10 & 5 & 5 & 5 & $8.64 \times 10^{7}$ & $8.60 \times 10^{7}$ \\
\hline 4 & 50 & 5 & 5 & 5 & $2.04 \times 10^{8}$ & $2.08 \times 10^{8}$ \\
\hline 5 & 30 & 3 & 3 & 3 & $2.02 \times 10^{7}$ & $4.51 \times 10^{7}$ \\
\hline 6 & 30 & 3 & 7 & 3 & $4.46 \times 10^{7}$ & $5.35 \times 10^{7}$ \\
\hline 7 & 30 & 3 & 3 & 7 & $2.12 \times 10^{7}$ & $1.88 \times 10^{7}$ \\
\hline 8 & 30 & 3 & 7 & 7 & $1.45 \times 10^{8}$ & $1.27 \times 10^{8}$ \\
\hline 9 & 10 & 3 & 5 & 3 & $6.72 \times 10^{7}$ & $6.57 \times 10^{7}$ \\
\hline 10 & 50 & 3 & 5 & 3 & $1.83 \times 10^{8}$ & $1.73 \times 10^{8}$ \\
\hline 11 & 10 & 3 & 5 & 7 & $7.62 \times 10^{7}$ & $9.06 \times 10^{7}$ \\
\hline 12 & 50 & 3 & 5 & 7 & $1.90 \times 10^{8}$ & $1.96 \times 10^{8}$ \\
\hline 13 & 30 & 1 & 3 & 5 & $1.85 \times 10^{7}$ & $1.65 \times 10^{7}$ \\
\hline 14 & 30 & 5 & 3 & 5 & $2.90 \times 10^{7}$ & $3.65 \times 10^{7}$ \\
\hline 15 & 30 & 1 & 7 & 5 & $5.59 \times 10^{7}$ & $5.23 \times 10^{7}$ \\
\hline 16 & 30 & 5 & 7 & 5 & $1.11 \times 10^{8}$ & $1.18 \times 10^{8}$ \\
\hline 17 & 10 & 3 & 3 & 5 & $6.70 \times 10^{4}$ & $-1.60 \times 10^{7}$ \\
\hline 18 & 50 & 3 & 3 & 5 & $6.09 \times 10^{7}$ & $4.97 \times 10^{7}$ \\
\hline 19 & 10 & 3 & 7 & 5 & $1.03 \times 10^{6}$ & $2.10 \times 10^{6}$ \\
\hline 20 & 50 & 3 & 7 & 5 & $1.41 \times 10^{8}$ & $1.48 \times 10^{8}$ \\
\hline 21 & 30 & 1 & 5 & 3 & $1.03 \times 10^{8}$ & $9.55 \times 10^{7}$ \\
\hline 22 & 30 & 5 & 5 & 3 & $1.75 \times 10^{8}$ & $1.62 \times 10^{8}$ \\
\hline 23 & 30 & 1 & 5 & 7 & $1.40 \times 10^{8}$ & $1.44 \times 10^{8}$ \\
\hline 24 & 30 & 5 & 5 & 7 & $1.64 \times 10^{8}$ & $1.62 \times 10^{8}$ \\
\hline 25 & 30 & 3 & 5 & 5 & $1.49 \times 10^{8}$ & $1.51 \times 10^{8}$ \\
\hline 26 & 30 & 3 & 5 & 5 & $1.59 \times 10^{8}$ & $1.51 \times 10^{8}$ \\
\hline 27 & 30 & 3 & 5 & 5 & $1.49 \times 10^{8}$ & $1.51 \times 10^{8}$ \\
\hline 28 & 30 & 3 & 5 & 5 & $1.38 \times 10^{8}$ & $1.51 \times 10^{8}$ \\
\hline 29 & 30 & 3 & 5 & 5 & $1.59 \times 10^{8}$ & $1.51 \times 10^{8}$ \\
\hline
\end{tabular}

Note. STD = Standard; Factor $A=$ Purple yam concentration; Factor $B=$ Dextrose concentration; Factor $C$ $=\mathrm{pH}$; Factor $D=$ Inoculum size 
$Y=-438662875+(2240225 A)+$ where $Y$ is the predicted biomass of $S$. $(17592250 B)+(178699166.66667 C)$ cerevisiae (cells $/ \mathrm{mL})$, and $A, B, C$, and $+(-9565833.3333334 D)+D$ are the coded variables of purple yam $(199787.49999999 A B)+(504125 A C)$ concentration, dextrose concentration, $\mathrm{pH}$, $+(-13562.5 A D)+(2838437.5 B C)$ and inoculum size, respectively.

$+(-3031875 B D)+(6258437.5 C D) \quad$ ANOVA for the investigation of the $+\left(-44013.333333334 A^{2}\right)$ model adequacy is presented in Table 3 . $+\left(-1993677.0833334 B^{2}\right)$ The result of ANOVA with $p$-value of $+\left(21902458.333333 C^{2}\right)+5.45 \times 10^{-9}$ and $F$-value of 42.14 revealed $\left(-627614.58333333 D^{2}\right)$

[1] that the model was highly significant. The coefficient of determination $\mathrm{R}^{2}$ of 0.9768

Table 3

ANOVA for response surface regression model of Saccharomyces cerevisiae biomass production

\begin{tabular}{lccccc}
\hline Source & SS & df & MS & $F$-value & $p$-value \\
\hline Model & $1.08 \times 10^{17}$ & 14 & $7.72 \times 10^{15}$ & 42.14 & $5.45 \times 10^{-9 *}$ \\
\hline A & $3.37 \times 10^{16}$ & 1 & $3.37 \times 10^{16}$ & 184 & $1.90 \times 10^{-9 *}$ \\
B & $5.45 \times 10^{15}$ & 1 & $5.45 \times 10^{15}$ & 29.73 & $8.51 \times 10^{-5 *}$ \\
$\mathrm{C}$ & $1.02 \times 10^{16}$ & 1 & $1.02 \times 10^{16}$ & 55.85 & $2.99 \times 10^{-6 *}$ \\
$\mathrm{D}$ & $1.69 \times 10^{15}$ & 1 & $1.69 \times 10^{15}$ & 9.26 & $0.0087^{*}$ \\
$\mathrm{AB}$ & $2.55 \times 10^{14}$ & 1 & $2.55 \times 10^{14}$ & 1.39 & 0.2574 \\
$\mathrm{AC}$ & $1.62 \times 10^{15}$ & 1 & $1.62 \times 10^{15}$ & 8.87 & $0.0099^{*}$ \\
$\mathrm{AD}$ & $1.17 \times 10^{11}$ & 1 & $1.17 \times 10^{11}$ & 0.006 & 0.9372 \\
$\mathrm{BC}$ & $5.15 \times 10^{14}$ & 1 & $5.15 \times 10^{14}$ & 2.81 & 0.1156 \\
$\mathrm{BD}$ & $5.88 \times 10^{14}$ & 1 & $5.88 \times 10^{14}$ & 3.20 & 0.0948 \\
$\mathrm{CD}$ & $2.50 \times 10^{15}$ & 1 & $2.50 \times 10^{15}$ & 13.67 & $0.0023^{*}$ \\
$A^{2}$ & $2.01 \times 10^{15}$ & 1 & $2.01 \times 10^{15}$ & 10.96 & $0.0051^{*}$ \\
$B^{2}$ & $4.12 \times 10^{14}$ & 1 & $4.12 \times 10^{14}$ & 271.57 & 0.1558 \\
$C^{2}$ & $4.97 \times 10^{14}$ & 1 & $4.97 \times 10^{14}$ & 202.49 & $1.45 \times 10^{-10 *}$ \\
$D^{2}$ & $4.08 \times 10^{12}$ & 1 & $4.08 \times 10^{12}$ & 0.22 & 0.6440 \\
\hline Lack of fit & $2.27 \times 10^{15}$ & 10 & $2.27 \times 10^{14}$ & 3.07 & 0.1455 \\
\hline Pure error & $2.95 \times 10^{14}$ & 4 & $7.39 \times 10^{12}$ & & \\
\hline Cor total & $1.10 \times 10^{17}$ & 28 & & & \\
\hline $\mathrm{R}^{2}=0.9768$ & & & & & \\
Adjusted $\mathrm{R}^{2}=0.9536$ & & & & & \\
Predicted $\mathrm{R}^{2}=0.8777$ & & & & \\
\hline Note Si & & & & \\
\hline
\end{tabular}

Note. $*$ Significant $(p<0.05) ; \mathrm{SS}=$ Sum of squares; $\mathrm{df}=$ Degrees of freedom; $\mathrm{MS}=$ Mean square; $A=$ Purple yam concentration; $B=$ Dextrose concentration; $C=\mathrm{pH} ; D=$ Inoculum size; $A B=$ Purple yam concentration $\times$ Dextrose concentration; $A C=$ Purple yam concentration $\times \mathrm{pH} ; A D=$ Purple yam concentration $\times$ Inoculum size; $B C=$ Dextrose concentration $\times \mathrm{pH} ; B D=$ Dextrose concentration $\times$ Inoculum size; $C D=\mathrm{pH} \times$ Inoculum size; $A^{2}=$ Purple yam concentration $\times$ Purple yam concentration; $B^{2}=$ Dextrose concentration $\times$ Dextrose concentration; $C^{2}=\mathrm{pH} \times \mathrm{pH} ; D^{2}=$ Inoculum size $\times$ Inoculum size 
and the adjusted coefficient of determination $\mathrm{R}^{2}$ of 0.9536 were high and close to 1 , indicating the good correlation between the factors and the response (Kamal et al., 2019) and the suitability of the model ( $\mathrm{Hu}$ et al., 2016). Besides, the lack of fit was not significant, which displayed that the regression equation of this study is good and acceptable (Islam Shishir et al., 2016). These results, therefore, indicated that the response surface regression model is reliable and accurate in predicting and investigating the optimal conditions for the biomass production of $S$. cerevisiae in PYDB.

As shown in Table 3, all independent variables in this optimization consist of purple yam concentration, dextrose concentration, $\mathrm{pH}$, and inoculum size greatly affected the biomass production of $S$. cerevisiae in PYDB, because the $p$-value of the linear term of every variable $(A, B$, $C$, and $D$ ) and quadratic term of purple yam concentration $\left(A^{2}\right)$ and $\mathrm{pH}\left(C^{2}\right)$ were very significant. The interaction effect of purple yam concentration and $\mathrm{pH}(A C)$, as well as $\mathrm{pH}$ and inoculum size $(C D)$ also affected $S$. cerevisiae growth in PYDB.

The three-dimensional (3D) response surface curves and their corresponding two-dimensional (2D) contour plots are generally the graphical representations of the relationship between the variables and response, which were generated from the regression model (Figures 4A-F). Each $3 \mathrm{D}$ response surface with $2 \mathrm{D}$ plot demonstrates the predicted response of the combinations of two test variables with the other two variables were maintained at their center value. The impact of independent variables, the impact of the interaction effect of variables, and the optimal value of each variable for maximum biomass of $S$. cerevisiae in PYDB were also discovered with these graphical plots.

The concentration of components in the culture medium is one of the important factors that should be optimized for the highest biomass to accomplish the highest advantage of the production (Reihani \& Khosravi-Darani, 2019). There are only two components in the PYDB culture medium, purple yam, and dextrose. An increase in the concentration of purple yam (Figures 4A, 4B, and 4C) and dextrose (Figures $4 \mathrm{~A}, 4 \mathrm{D}$, and 4E) resulted in increased biomass production. The predicted optimal concentration of purple yam and dextrose in PYDB were 49.61 and $4.87 \%$, respectively. Hezarjaribi et al. (2016) found that the increase of glucose up to $5 \%$ also gave the highest biomass and single cell protein production from $S$. cerevisiae. Purple yam and dextrose are carbon and energy sources (Chandrasekara \& Kumar, 2016; Wanasundera \& Ravindran, 1994), both of which are essential sources for $S$. cerevisiae growth (Mitterdorfer et al., 2001). Dextrose is known to affect numerous processes in $S$. cerevisiae, but in fact, dextrose also has a profound effect on yeast gene transcription (Newcomb et al., 2003).

The $\mathrm{pH}$ in the culture medium is an important factor that affects the growth of S. cerevisiae (Kasemets et al, 2007). The predicted optimal $\mathrm{pH}$ of $S$. cerevisiae in PYDB was 5.74, resulting in the maximum 


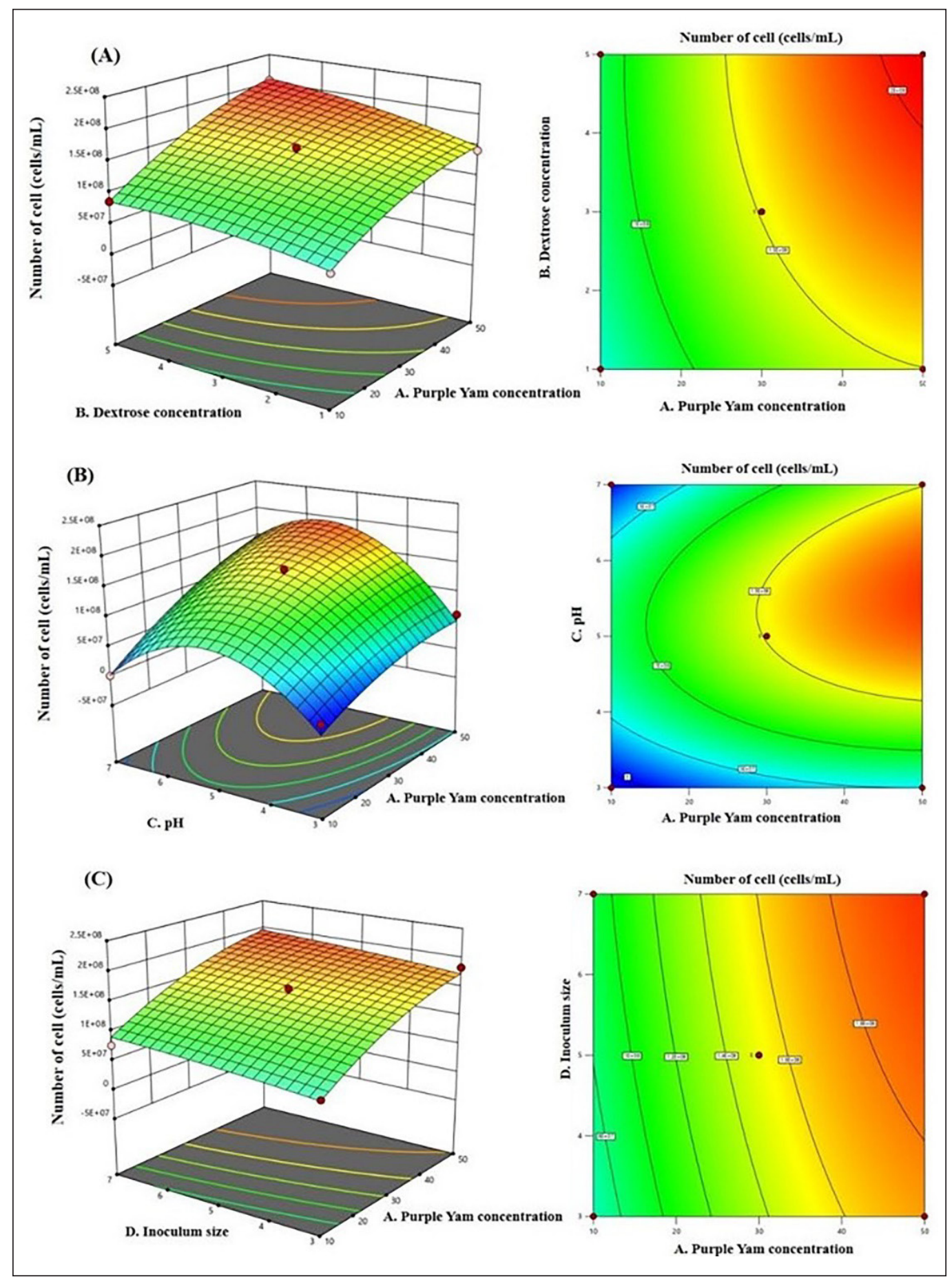

Figure 4. 3D response surface plots (left) and 2D contour plots (right) show the effect of (A) purple yam concentration and dextrose concentration; (B) purple yam concentration and $\mathrm{pH}$; (C) purple yam concentration and inoculum size on the number of Saccharomyces cerevisiae 


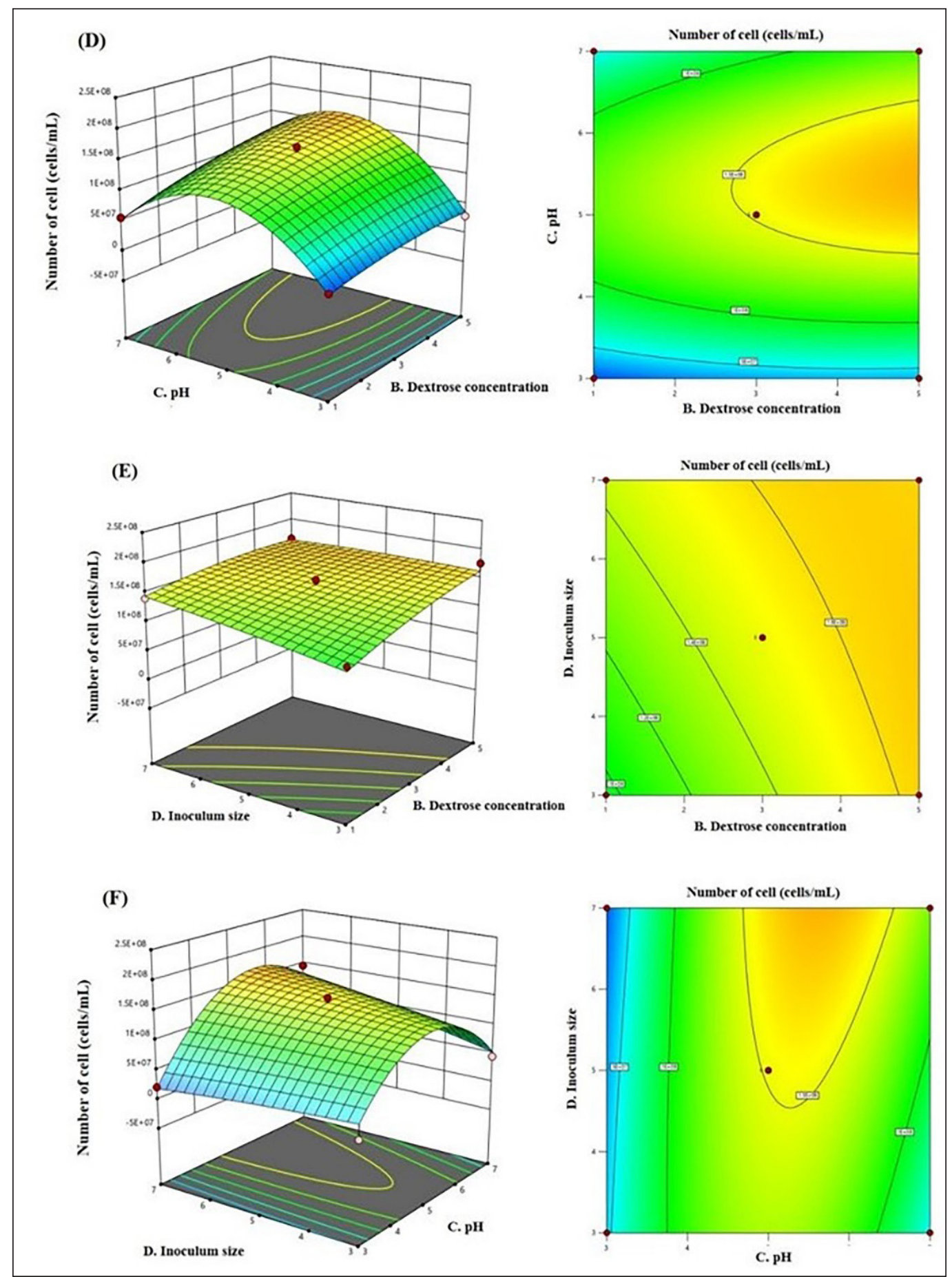

Figure 4 (continue). 3D response surface plots (left) and 2D contour plots (right) show the effect of (D) dextrose concentration and $\mathrm{pH}$; (E) dextrose concentration and inoculum size; (F) pH and inoculum size on the number of Saccharomyces cerevisiae 
biomass production of $S$. cerevisiae in PYDB (Figures 4B, 4D, and 4F). Most yeast thrives under acidic conditions than at neutral or alkaline conditions (Canadell et al., 2015; Narendranath \& Power, 2005). However, the biomass production of $S$. cerevisiae decreased under extremely acidic conditions (Noé Arroyo-López et al., 2009). The optimal $\mathrm{pH}$ of $S$. cerevisiae growth in each culture medium is different. The optimal $\mathrm{pH}$ for biomass production of $S$. cerevisiae in mineral salts medium supplemented with date extract was 5.35 (Kara Ali et al., 2017), while a $\mathrm{pH}$ value of 4.6 is optimum for $S$. cerevisiae in sweet potato dextrose broth (Wongjiratthiti \& Yottakot, 2017).

The inoculum size not only has a direct impact on the overall production yield (Ginovart et al., 2011; Jiru et al., 2017; Kamal et al., 2019; Reihani \& Khosravi-Darani, 2019), but it also affects the production cost (Reihani \& KhosraviDarani, 2019). The increase of the inoculum size has a positive effect on the production of $S$. cerevisiae biomass in PYDB (Figures $4 \mathrm{C}, 4 \mathrm{E}$, and $4 \mathrm{~F}$ ). The shortest lag phase and time for the first cell division were attained with the largest inoculum size (Ginovart et al., 2011). The optimal inoculum size differs for each type of microorganism in each type of culture medium (Reihani \& KhosraviDarani, 2019). The inoculum size of $7.00 \%$ was an optimal condition for the biomass production of $S$. cerevisiae in PYDB.

The interaction effect between purple yam concentration and $\mathrm{pH}$ is observed in Table 3 and Figure 4B, as well as between $\mathrm{pH}$ and inoculum size (Table 3 and Figure
4F). The ellipse was found to be slightly oblique in the contour plot of Figures $4 \mathrm{~B}$ and 4F. The optimal $\mathrm{pH}$ of $S$. cerevisiae in PYDB was slightly more neutral when the purple yam concentration was higher (Figure 4B), likewise, when the inoculum size was larger (Figure 4F). The yeast utilizes nutrients in the culture medium, and produces organic acids as the metabolic product, which affects to increase the acidity of the culture medium (Porro \& Branduardi, 2017).

The purple yam concentration of $49.61 \%$ and the dextrose concentration of $4.87 \%$ at $\mathrm{pH}$ value of 5.74 with $7.00 \%$ inoculum size were the predicted optimal culture conditions for the biomass production of $S$. cerevisiae in PYDB medium. The predicted S. cerevisiae biomass under these optimized conditions was $2.24 \times 10^{8}$ cells $/ \mathrm{mL}$ (Figure 5).

The validation of the predicted statistical result at optimized conditions was performed, and the comparison of this result with the predicted number of cells in PYDB under optimized conditions from the response regression model and the number of cells in PDB under standard conditions is shown in Figure 6. The experimental value of $2.20 \times 10^{8}$ cells $/ \mathrm{mL}$ resembles with the predicted value $\left(2.24 \times 10^{8}\right.$ cells/ $\mathrm{mL})$. A total of $2.20 \times 10^{8}$ cells $/ \mathrm{mL}$ was recorded when growing on PYDB under the optimized culture conditions, which is thirty times higher than the number of $S$. cerevisiae in $\mathrm{PDB}$ under standard conditions of $7.37 \times 10^{6}$ cells $/ \mathrm{mL}$. Therefore, in addition to the acceptable model, PYDB could be satisfactorily used for the biomass production of $S$. cerevisiae. 


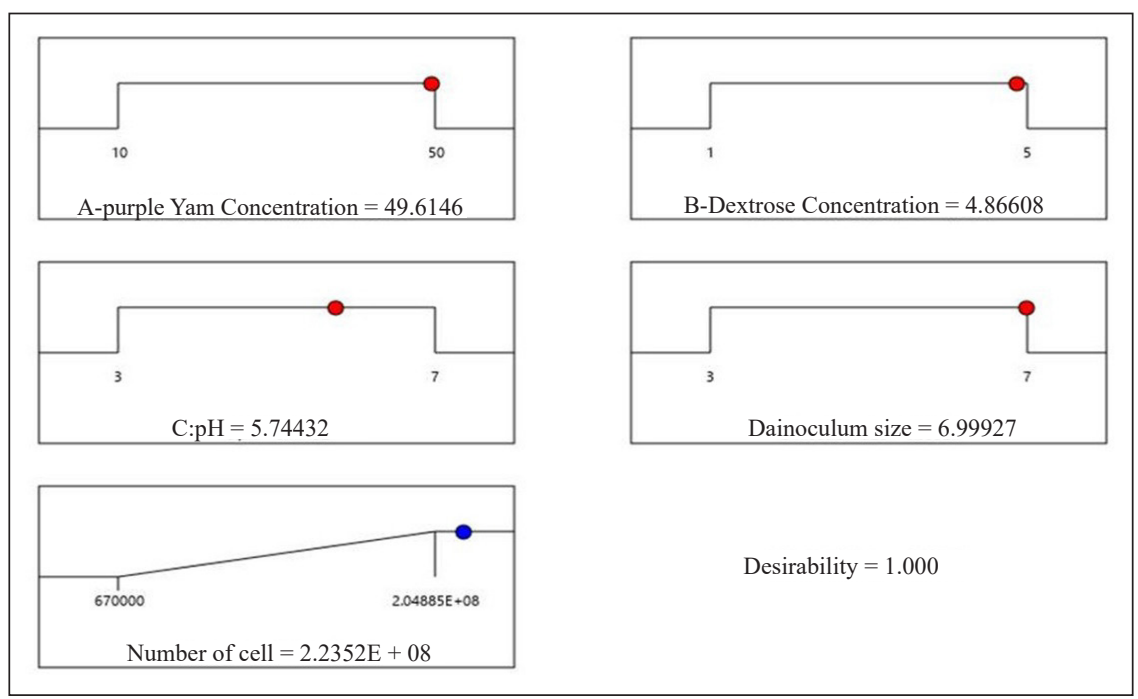

Figure 5. The optimal conditions of the independent variables and the predicted response

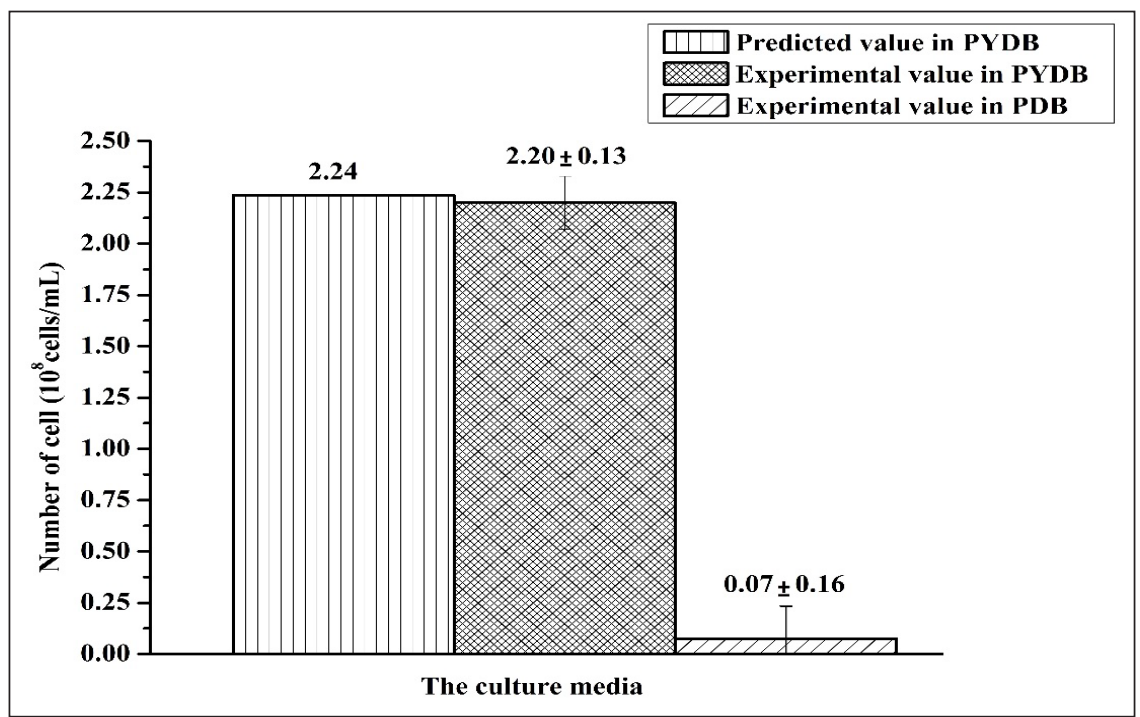

Figure 6. The comparison of the number of cells in purple yam dextrose broth (PYDB) under optimized conditions with the predicted value and the number of cells in potato dextrose broth (PDB) under standard conditions

\section{Growth Profile of Saccharomyces cerevisiae in PYDB under the Optimal Conditions Based on the Results of RSM}

The growth profile has been used for describing the microbial growth in broth media over time (Ram et al., 2019). The growth profile of Saccharomyces cerevisiae in PYDB under optimized culture conditions is shown in Figure 7. The lag phase of $S$. cerevisiae growth was found from the initial incubation period until 6 hours of 
incubation. The yeast takes a little time to accommodate itself to its new habitat and environment. The number of $S$. cerevisiae increased exponentially from the sixth hour of incubation to the twenty-fourth hour of incubation, this stage is called the exponential phase or logarithmic phase (log phase). In the late exponential phase, the diauxic shift was observed at the eighteenth hour of incubation when glucose was restricted, and the growth rate of $S$. cerevisiae in PYDB decreased from the eighteenth hour of incubation to the twentyfourth hour of incubation (the post-diauxic growth period) (Herman, 2002). The highest number of $S$. cerevisiae in PYDB under optimized culture conditions was found at the twenty-fourth hour of incubation, equal to $2.19 \times 10^{8} \pm 0.05$ cells $/ \mathrm{mL}$ (Figure 7 ). After that, the $S$. cerevisiae growth entered a stationary phase, observing from the constant number of cells. Therefore, the optimal incubation time of $S$. cerevisiae in PYDB under optimized culture conditions for $S$. cerevisiae biomass production was twenty-four hours.

\section{CONCLUSION}

The finding from this study concluded that purple yam has a high potential for utilization as alternative culture media in fungal cultivation. The growth of mushroom, mold, and yeast in PYDB media containing $40 \%$ purple yam was greater than potato dextrose media. In the same media, the biomass production and growth of Saccharomyces cerevisiae under optimized culture conditions were higher than those in PDB under standard conditions. The growth of $S$. cerevisiae in PYDB under optimized conditions was thirty times better than the growth of $S$. cerevisiae in PDB under standard conditions. Taken together,

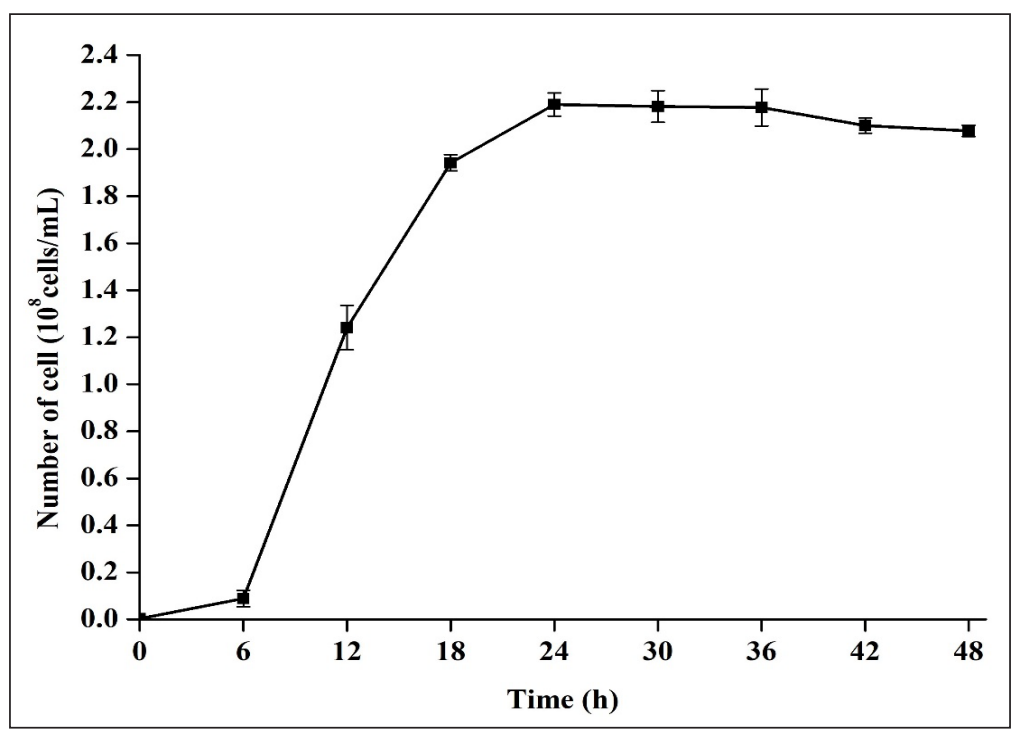

Figure 7. The growth profile of Saccharomyces cerevisiae in purple yam dextrose broth under optimized culture conditions 
purple yam is a suitable tuber crop and an alternative nutrient source for fungal cultivation. The biomass production of other fungi and their products using purple yam in the media preparation should be further studied.

\section{ACKNOWLEDGEMENTS}

This work was supported by Program of Biology, Faculty of Science and Technology, Sakon Nakhon Rajabhat University, Thailand.

\section{REFERENCES}

Adesemoye, A. O., \& Adedire, C. O. (2005). Use of cereals as basal medium for the formulation of alternative culture medium for fungi. World Journal of Microbiology and Biotechnology, 21(3), 329-336. https://doi.org/10.1007/s11274004-3907-4

Amadi, O. C., \& Moneke, A. N. (2012). Use of starch containing tubers for the formulation of culture media for fungal cultivation. African Journal of Microbiology Research, 6(21), 4527-4532. https://doi.org/10.5897/AJMR12.097

Arevalo-Villena, M., Briones-Perez, A., Corbo, M. R., Sinigaglia, M., \& Bevilacqua, A. (2017). Biotechnological application of yeasts in food science: Starter cultures, probiotics and enzyme production. Journal of Applied Microbiology, 123(6), 1360-1372. https://doi.org/10.1111/ jam. 13548

Bellettini, M. B., Fiorda, F. A., Maieves, H. A., Teixeira, G. L., Ávila, S., Hornung, P. S., Júnior, A. M., \& Ribani, R. H. (2019). Factors affecting mushroom Pleurotus spp. Saudi Journal of Biological Sciences, 26(4), 633-646. https://doi. org/10.1016/j.sjbs.2016.12.005
Canadell, D., García-Martínez, J., Alepuz, P., Pérez-Ortín, J. E., \& Ariño, J. (2015). Impact of high $\mathrm{pH}$ stress on yeast gene expression: A comprehensive analysis of mRNA turnover during stress responses. Biochimica et Biophysica Acta (BBA) - Gene Regulatory Mechanisms, 1849(6), 653-664. http://doi.org/10.1016/j. bbagrm.2015.04.001

Chandrasekara, A., \& Kumar, J. T. (2016). Roots and tuber crops as functional foods: A review on phytochemical constituents and their potential health benefits. International Journal of Food Science, 2016, 3631647. https://doi. org/10.1155/2016/3631647

Dinarvand, M., Rezaee, M., \& Foroughi, M. (2017). Optimizing culture conditions for production of intra and extracellular inulinase and invertase from Aspergillus niger ATCC 20611 by response surface methodology (RSM). Brazilian Journal of Microbiology, 48(3), 427-441. https://doi. org/10.1016/j.bjm.2016.10.026

Farinazzo, F. S., Farinazzo, E. S., Spinosa, W. A., \& Garcia, S. (2017). Saccharomyces boulardii: Optimization of simultaneous saccharification and fermentation of cell production in organic and conventional apple substrate pulp. Food Science and Biotechnology, 26(4), 969-977. https://doi.org/10.1007/s10068-017-0123-1

Ginovart, M., Prats, C., Portell, X., \& Silbert, M. (2011). Exploring the lag phase and growth initiation of a yeast culture by means of an individual-based model. Food Microbiology, 28(4), 810-817. https://doi.org/10.1016/j. fm.2010.05.004

Herman, P. K. (2002). Stationary phase in yeast. Current Opinion in Microbiology, 5(6), 602-607. https://doi.org/10.1016/S1369-5274(02)00377-6

Hezarjaribi, M., Ardestani, F., \& Ghorbani, H. R. (2016). Single cell protein production by Saccharomyces cerevisiae using an optimized 
culture medium composition in a batch submerged bioprocess. Applied Biochemistry and Biotechnology, 179(8), 1336-1345. https:// doi.org/10.1007/s12010-016-2069-9

Hoa, H. T., \& Wang, C. L. (2015). The effects of temperature and nutritional conditions on mycelium growth of two oyster mushrooms (Pleurotus ostreatus and Pleurotus cystidiosus). Mycobiology, 43(1), 14-23. https://doi. org/10.5941/MYCO.2015.43.1.14

Hu, Y., Qin, H., Zhan, Z., Dun, Y., Zhou, Y., Peng, N., Ling, H., Liang, Y., \& Zhao, S. (2016). Optimization of Saccharomyces boulardii production in solid-state fermentation with response surface methodology. Biotechnology and Biotechnological Equipment, 30(1), 173179. https://doi.org/10.1080/13102818.2015.1 086689

Hucker, B., Wakeling, L., \& Vriesekoop, F. (2016). Vitamins in brewing: Presence and influence of thiamine and riboflavin on wort fermentation. Journal of the Institute of Brewing, 122(1), 126-137. https://doi.org/10.1002/jib.293

Islam Shishir, M. R., Taip, F. S., Aziz, N. A., Talib, R. A., \& Hossain Sarker, M. S. (2016). Optimization of spray drying parameters for pink guava powder using RSM. Food Science and Biotechnology, 25(2), 461-468. https://doi. org/10.1007/s10068-016-0064-0

Jiru, T. M., Groenewald, M., Pohl, C., Steyn, L., Kiggundu, N., \& Abate, D. (2017). Optimization of cultivation conditions for biotechnological production of lipid by Rhodotorula kratochvilovae (syn, Rhodosporidium kratochvilovae) SY89 for biodiesel preparation. 3 Biotech, 7(2), 145. https://doi.org/10.1007/s13205-017-0769-7

Kamal, M. M., Ali, M. R., Shishir, M. R. I., Saifullah, M., Haque, M. R., \& Mondal, S. C. (2019). Optimization of process parameters for improved production of biomass protein from Aspergillus niger using banana peel as a substrate. Food Science and Biotechnology, 28(6), 1693-1702. https://doi.org/10.1007/s10068-019-00636-2

Kara Ali, M., Outili, N., Ait Kaki, A., Cherfia, R., Benhassine, S., Benaissa, A., \& Kacem Chaouche, N. (2017). Optimization of baker's yeast production on date extract using response surface methodology (RSM). Foods, 6(8), 64. https://doi.org/10.3390/foods6080064

Karathia, H., Vilaprinyo, E., Sorribas, A., \& Alves, R. (2011). Saccharomyces cerevisiae as a model organism: A comparative study. PLOS One, 6(2), e16015. https://doi.org/10.1371/journal. pone. 0016015

Kasemets, K., Nisamedtinov, I., Laht, T. M., Abner, K., \& Paalme, T. (2007). Growth characteristics of Saccharomyces cerevisiae S288C in changing environmental conditions: Auxo-accelerostat study. Antonie van Leeuwenhoek, 92(1), 109128. https://doi.org/10.1007/s10482-007-9141-y

Kittipadakul, P., Jaipeng, B., Slater, A., Stevenson, W., \& Jansky, S. (2016). Potato production in Thailand. American Journal of Potato Research, 93(4), 380-385. https://doi.org/10.1007/s12230016-9511-y

Kot, A. M., Błażejak, S., Kieliszek, M., Gientka, I., \& Bryś, J. (2019). Simultaneous production of lipids and carotenoids by the red yeast Rhodotorula from waste glycerol fraction and potato wastewater. Applied Biochemistry and Biotechnology, 189(2), 589-607. https://doi. org/10.1007/s12010-019-03023-z

Laurie, S., Faber, M., Adebola, P., \& Belete, A. (2015). Biofortification of sweet potato for food and nutrition security in South Africa. Food Research International, 76(Part 4), 962-970. https://doi. org/10.1016/j.foodres.2015.06.001

Li, M., Petteys, B. J., McClure, J. M., Valsakumar, V., Bekiranov, S., Frank, E. L., \& Smith, J. S. (2010). Thiamine biosynthesis in Saccharomyces 
cerevisiae is regulated by the $\mathrm{NAD}^{+}$-dependent histone deacetylase Hst1. Molecular and Cellular Biology, 30(13), 3329-3341. https:// doi.org/10.1128/MCB.01590-09

Mad Saad, M. E., Farah Amani, A. H., \& Lee, C. K. (2016). Optimization of bioethanol production process using oil palm frond juice as substrate. Malaysian Journal of Microbiology, 12(4), 308-314. http://doi.org/10.21161/mjm.84016

Mitterdorfer, G., Kneifel, W., \& Viernstein, H. (2001). Utilization of prebiotic carbohydrates by yeasts of therapeutic relevance. Letters in Applied Microbiology, 33(4), 251-255. https://doi. org/10.1046/j.1472-765X.2001.00991.x

Moddaeng, V., \& Khompun, W. (2019). การพัฒนา อาหารสำหรับเลียงราก่อโรค Curvularia lunata และ Fusarium solani โดยใช้หัวพืชสกุลกลอยบางชนิด [Culture media development for pathogenic fungi Curvularia lunata and Fusarium solani using tubers of some Dioscorea species]. Khon Kaen Agriculture Journal, 47(Suppl. 1), 1619-1626.

Narendranath, N. V., \& Power, R. (2005). Relationship between $\mathrm{pH}$ and medium dissolved solids in terms of growth and metabolism of lactobacilli and Saccharomyces cerevisiae during ethanol production. Applied and Environmental Microbiology, 71(5), 2239-2243. https://doi. org/10.1128/AEM.71.5.2239-2243.2005

Newcomb, L. L., Diderich, J. A., Slattery, M. G., \& Heideman, W. (2003). Glucose regulation of Saccharomyces cerevisiae cell cycle genes. Eukaryotic cell, 2(1), 143-149. https://doi. org/10.1128/EC.2.1.143-149.2003

Nguyen, T. M., \& Ranamukhaarachchi, S. L. (2020). Effect of different culture media, grain sources and alternate substrates on the mycelial growth of Pleurotus eryngii and Pleurotus ostreatus. Pakistan Journal of Biological Sciences, 23(3), 223-230. https://doi.org/10.3923/ pjbs.2020.223.230
Noé Arroyo-López, F., Orlić, S., Querol, A., \& Barrio, E. (2009). Effects of temperature, $\mathrm{pH}$ and sugar concentration on the growth parameters of Saccharomyces cerevisiae, $S$. kudriavzevii and their interspecific hybrid. International Journal of Food Microbiology, 131(2-3), 120-127. https://doi.org/10.1016/j. ijfoodmicro.2009.01.035

Parapouli, M., Vasileiadis, A., Afendra, A. S., \& Hatziloukas, E. (2020). Saccharomyces cerevisiae and its industrial applications. AIMS Microbology, 6(1), 1-31. https://doi. org/10.3934/microbiol.2020001

Porro, D., \& Branduardi, P. (2017). Production of organic acids by yeasts and filamentous fungi. In A. A. Sibirny (Ed.), Biotechnology of yeasts and filamentous fungi (pp. 205-223). Springer International Publishing AG. https:// doi.org/10.1007/978-3-319-58829-2_7

Ram, Y., Dellus-Gur, E., Bibi, M., Karkare, K., Obolski, U., Feldman, M. W., Cooper, T. F., Berman, J., \& Hadany, L. (2019). Predicting microbial growth in a mixed culture from growth curve data. Proceedings of the National Academy of Sciences of the United States of America, 116(29), 14698-14707. https://doi.org/10.1073/ pnas. 1902217116

Reihani, S. F. S., \& Khosravi-Darani, K. (2019). Influencing factors on single cell protein production by submerged fermentation: A review. Electronic Journal of Biotechnology, 37, 34-40. https://doi.org/10.1016/j.ejbt.2018.11.005

Sharmila, G., Nidhi, B., \& Muthukumaran, C. (2013). Sequential statistical optimization of red pigment production by Monascus purpureus (MTCC 369) using potato powder. Industrial Crops and Products, 44, 158-164. https://doi.org/10.1016/j. indcrop.2012.11.007

Shiroma, S., Jayakody, L. N., Horie, K., Okamoto, K., \& Kitagaki, H. (2013). Enhancement of ethanol fermentation in Saccharomyces cerevisiae sake 
yeast by disrupting mitophagy function. Applied and Environmental Microbiology, 80(3), 10021012. https://doi.org/10.1128/AEM.03130-13

Shu, G., Yang, X., Chen, L., Huang, D., Lei, Z., \& Chen, H. (2020). Statistical optimization of cultivation conditions for Saccharomyces boulardii via central composite design. Scientific Study and Research, 21(2), 227-242.

Singh, U. S., \& Kapoor, K. (2010). Introduction microbiology. Oxford Book Company.

Tayeb, A. M., Tony, M. A., \& Mansour, S. A. (2018). Application of Box-Behnken factorial design for parameters optimization of basic dye removal using nano-hematite photo-Fenton tool. Applied Water Science, 8(5), 138. https://doi.org/10.1007/ s13201-018-0783-x

Uraz, T., \& Özer, B. H. (2014). Starter cultures: Molds employed in food processing. In C. A. Batt \& M. L. Tortorello (Eds.), Encyclopedia of food microbiology (pp. 522-528). Academic Press. https://doi.org/10.1016/B978-0-12-384730$0.00323-2$

Vargas-Isla, R., \& Ishikawa, N. K. (2008). Optimal conditions of in vitro mycelial growth of Lentinus strigosus, an edible mushroom isolated in the Brazilian Amazon. Mycoscience, 49(3), 215219. https://doi.org/10.1007/S10267-007-0404-2

Walker, G., \& Stewart, G. (2016). Saccharomyces cerevisiae in the production of fermented beverages. Beverages, 2(4), 30. https://doi. org/10.3390/beverages 2040030

Wanasundera, J. P. D., \& Ravindran, G. (1994). Nutritional assessment of yam (Dioscorea alata) tubers. Plant Foods for Human Nutrition, 46(1), 33-39. https://doi.org/10.1007/BF01088459

Wongjiratthiti, A., \& Yottakot, S. (2017). Utilisation of local crops as alternative media for fungal growth. Pertanika Journal of Tropical Agricultural Science, 40(2), 295-304.

Xiao, J. H., Chen, D. X., Liu, J. W., Liu, Z. L., Wan, W. H, Fang, N., Xiao, Y., Qi, Y., \& Liang, Z. Q. (2004). Optimization of submerged culture requirements for the production of mycelial growth and exopolysaccharide by Cordyceps jiangxiensis JXPJ 0109. Journal of Applied Microbiology, 96(5), 1105-1116. https://doi. org/10.1111/j.1365-2672.2004.02235.x 